\title{
Diagnostic and Therapeutic Options of Breast Cancer Patients in Yaounde, Cameroon
}

\author{
Jean Dupont Kemfang Ngowa ${ }^{1^{*}}\left(\mathbb{D}\right.$, Hortense Jeanne Fouedjio' ${ }^{1}$, Annaïk Morelle Tchami ${ }^{2}$, \\ Julienne Louise Ngo Likeng3, Christelle Domngang Noche2, Brigitte Wandji Djouonang1, \\ Florent Fouelifack Ymele4, Pascal Foumane', Emile Telesphore Mboudou ${ }^{1}$, Pierre Marie Tebeu ${ }^{1}$
}

\author{
${ }^{1}$ Faculty of Medicine and Biomedical Sciences, University of Yaounde I, Yaounde, Cameroon \\ ${ }^{2}$ University of Montagnes, Bangangté, Cameroon \\ ${ }^{3}$ Catholic University of Central Africa, Yaounde, Cameroon \\ ${ }^{4}$ Higher Institute of Medical Technology, Nkolondom, Cameroon \\ Email: ${ }^{\star j d k e m f a n g @ y a h o o . f r ~}$
}

How to cite this paper: Ngowa, J.D.K., Fouedjio, H.J., Tchami, A.M., Likeng, J.L.N., Noche, C.D., Djouonang, B.W., Ymele, F.F., Foumane, P., Mboudou, E.T. and Tebeu, P.M. (2022) Diagnostic and Therapeutic Options of Breast Cancer Patients in Yaounde, Cameroon. Advances in Breast Cancer Research, 11, 50-62.

https://doi.org/10.4236/abcr.2022.111003

Received: December 20, 2021

Accepted: January 22, 2022

Published: January 25, 2022

Copyright (c) 2022 by author(s) and Scientific Research Publishing Inc. This work is licensed under the Creative Commons Attribution International License (CC BY 4.0).

http://creativecommons.org/licenses/by/4.0/

\begin{abstract}
Introduction: Breast cancer remains a public health problem due to its severity and because it is the leading cause of death from cancers in women worldwide as well as in Cameroon. Our objective was to study the diagnostic and therapeutic options that patients followed for breast cancer choose in Yaounde. Method: This was an analytical cross-sectional study with prospective data collection among patients followed for breast cancer at two referral hospitals in Yaounde from February 1, 2019 to August 31, 2019. Data collected were recorded and analyzed using $\mathrm{R}$ application version 3.5.0., $\mathrm{p}$ values $<0.05$ were considered to be statistically significant. Results: A total of 105 patients were recruited, including 104 women and 1 man. The median age was 46 years with extremes of 25 and 77 years. Most patients (71\%) had a monthly income of less than 175 USD. Patients in this study had opted for: contemporary medicine $(49.5 \%)$, therapeutic abstention (38.1\%), naturopathy (1.9\%), self-medication $(9.5 \%)$ and traditional medicine (1\%). The factors significantly associated with the choice of contemporary medicine as a first diagnostic option were monthly income above 175 USD (OR $=0.37,95 \%$ CI: $0.15-0.89, \mathrm{p}=$ $0.028)$, good level of education ( $O R=0.37,95 \% \mathrm{CI}: 0.16-0.82, \mathrm{p}=0.034)$ and good knowledge about breast cancer $(\mathrm{OR}=0.28,95 \% \mathrm{CI}: 0.08-0.89, \mathrm{p}=$ $0.005)$. The majority of patients $(65.7 \%)$ sought contemporary medicine as the first therapeutic option after a diagnosis of breast cancer was confirmed, while about a third of them had chosen alternative treatment options including naturopathy (15.2\%), traditional medicine $(9.5 \%)$, religious practices $(4.8 \%)$, therapeutic abstention (2.9\%) and self-medication (1.9\%). Conclusion: The first diagnostic and therapeutic choices of breast cancer patients in our setting are
\end{abstract}


numerous and intricate, including contemporary medicine, therapeutic abstention, self-medication, traditional medicine, naturopathy and religious practices. There is a need to promote breast cancer awareness in our population.

\section{Keywords}

Breast Cancer, Traditional Medicine, Therapeutic Abstention, Naturopathy, Contemporary Medicine

\section{Introduction}

Breast cancer is an abnormal and anarchical development of cells in the mammary glands. It is the most frequent cancer in women worldwide with about 2 million new cases reported annually. It represents $23 \%$ of all female cancers and $11.6 \%$ of all human cancers according to Globocan 2018 report. Mortality of this cancer is estimated at $6.6 \%$ worldwide [1].

Breast cancer represents a major public health problem given its rapidly increasing incidence and its mortality. In 2008, almost 1.4 million women were diagnosed with breast cancer worldwide. Even though it is the first cause of death due to cancer worldwide, the mortality rates are higher in developing countries [2].

As the incidence increases, it is paralleled by a concomitant increase in morbidmortality [3]. In more developed countries about $70 \%$ of cases are diagnosed in stages I and II, while only $20 \%$ to $50 \%$ of cases in less developed countries are diagnosed in these stages with subsequent low survival rates [4] [5] [6]. This is rather unfortunate given that timely management at early stages remains a determining factor for the outcome of treatment, furthermore, early management is not only much easier but equally cost-effective compared to treatment of advancedstage cancers [2]. An in depth comprehension of the factors which influence delay to treatment is vital to ameliorating the survival rates of this cancer's patients [4]. The marked difference in the results of cancer treatment in women in developed countries compared to those in less developed countries warrants that the obstacles to early diagnosis and treatment in African women should be examined [2].

A study conducted in Cameroon revealed that consultation, diagnostic and treatment delays of breast cancer are long compared to those reported in developed countries [6]. The situation is also characterized by low survival rates of $30 \%$ at 5 years and $13.2 \%$ at 10 years which is much less compared to the corresponding $90 \%$ and $82 \%$ values at 5 and 10 years respectively in some developed countries [5] [7]. The long delays of consultation after the onset of the first symptoms could justify partly the late stages at the time of diagnosis. The obstacles to early consultation could be the beliefs and cultural considerations of the patients with 
respect to the disease, the low financial potential, as well as geographical barriers to diagnosis and management options [8]. Faced with these barriers to early consultation, the patients thus tend to adopt alternative means to seek solutions.

This raises the hypothesis that there exist different diagnostic and therapeutic choices used by these patients. The multiple routes taken by the patients after initial symptoms and even after a confirmatory diagnosis have been made participate in prolonging the delay till management. Patients usually consult in several different places without obtaining any definitive diagnosis. After the diagnosis of cancer is confirmed, they still engage in different itineraries hence further enhancing the delay. All of these have an impact on retarding the diagnosis and management of their disease [9]. For an in depth understanding of these delays, we sought to study the patients' choices after initial symptoms (diagnostic) and after confirmed diagnosis (therapeutic) in a group of patients followed up for breast cancer in two referral hospitals at Yaounde.

\section{Methods}

We carried out a cross-sectional analytical study on diagnostic and therapeutic choices of breast cancer patients followed from December 2018 to August 2019 in two university teaching hospitals: The Yaounde General Hospital and The Yaounde Gyneco-Obstetric and Paediatric Hospital which have both the human and material resources necessary to manage breast cancers. The recruitment of breast cancer patients and the analysis of data were done over a period of 6 months from 1st February 2019 to 31st October 2019. All consenting patients followed up during this period were included. We excluded non-consenting women and those who could not answer the questions. A consecutive and exhaustive non probability sampling method was used and the minimum sample size calculated was 30 according to the Cochrane's formula using incidence of new cases of breast cancer in Cameroon of $20.1 \%$ [10]. Using a pre-tested questionnaire, we collected the variables of interest from the patients and from the hospital registers. The variables of interest were sociodemographic parameters, socio-economic parameters (monthly revenue, availability of financial support, monthly expenditure for breast cancer care, health insurance coverage), the first symptoms of breast cancer observed, date of discovery of the first symptom, different initial measures taken and the reasons motivating the choices, the stage of the disease at diagnosis, the histological type, the current treatment. Also, the level of knowledge on breast cancer was assessed (its definition, risk factors, symptoms, high risk population, the methods of screening and their usage of the methods, its curability, the different treatment options and their actions). They had to respond by either "yes", "no"; "I don't know" or chose among preconceived phrases. Each correct answer weighed 1 point and each wrong answer 0 point. A total mark was calculated at the end. The overall score was on 8 . The appreciation of their level of knowledge was done using a scaling system used for evaluating knowledge, attitudes and practices which stipulates that: $<25 \%$ of correct answers = poor; $25 \%$ to $49 \%=$ insufficient; $50 \%$ to $70 \%=$ average; $>70 \%$ 
$=\operatorname{good}[11]$.

Data was entered into Excel and exported to the $\mathrm{R}$ application version 3.5.0 for statistical analysis. Contingency tables were drawn between the characteristics of patients and their first diagnostic and therapeutic choice. Multivariate logistic regressions were used to identify the determinants of the first choice. Only indicators which were significantly linked by at least $10 \%$ in univariate analysis were included in multivariate analysis. Multicollinearity tests between the variables were evaluated with the aid of the variance inflation factor. Forward and backward stepwise selection was used to obtain the best adjustment model. P-values were obtained using Wald test. Globally, the level of significance was 5\%. Ethical clearance was obtained from the Institutional Review Board of "University des Montagnes".

\section{Results}

A total of 105 participants were included in this study with a median age of 46 years and extremes of 25 years and 77 years. Most of the patients were married and had secondary school level of education (Table 1). Majority of the patients (71.43\%) had a monthly income of less than 175 USD. However, they estimated their monthly expenditures for breast cancer to be above 875 USD, which was mostly supported by their personal efforts since they had not subscribed to any form of health insurance (Table 2). They however benefitted from financial support from their families and friends occasionally. Most of the patients had advanced disease; $42.86 \%$ in stage 4 and $27.62 \%$ in stage 3 breast cancer. The most common histological type was invasive ductal carcinoma (Table 3 ).

Concerning their level of knowledge on breast cancer, most of the patients (63.81\%) could define breast cancer, only $33.33 \%$ knew that risk factors of breast cancer are natural, while $05.71 \%$ believed that they were mystical or spiritual. Breast mass was known to be a symptom of breast cancer by $54.29 \%$ of patients. Most patients were well informed about breast cancer screening methods (64.76\%) and treatment modalities (80\%) (Table 4).

The knowledge scores on breast cancer were good in $42 \%$ of participants, average in $17 \%$, insufficient in $24 \%$ and poor in $16 \%$ (Figure 1 ).

Concerning the factors associated to first choices at the discovery of initial symptoms of breast cancer, monthly revenue greater than 175 USD (OR $=0.37,95 \%$ CI: $0.15-0.89, \mathrm{p}=0.028)$, average of standard of living (OR $=0.37,95 \% \mathrm{CI}: 0.16$ - $0.82, \mathrm{p}=0.034)$ and good level of knowledge on the disease $(\mathrm{OR}=0.28,95 \%$ CI: $0.08-0.89, \mathrm{p}=0.005)$ were significantly associated to choosing contemporary medicine as first option (Table 5).

Concerning the reasons for making choices, $35.19 \%$ of patients received advice from a relative, $08.57 \%$ from a health care professional and $47.62 \%$ of cases were personal initiatives (Table 6).

At the discovery of the first breast symptoms, breast cancer patients had as first recourse, contemporary medicine in $49.5 \%$, therapeutic abstention in $38.1 \%$, self-medication in $9.5 \%$, naturopathy in $1.9 \%$, traditional medicine in $1 \%$. Among 
Table 1. Distribution of study population with respect to sociodemographic characteristics.

\begin{tabular}{|c|c|c|}
\hline Characteristic & $\begin{array}{l}\text { Number } \\
(\mathrm{N}=105)\end{array}$ & Percentage \\
\hline \multicolumn{3}{|l|}{ Age (Years) } \\
\hline$[20,30]$ & 5 & 4.76 \\
\hline$] 30,40]$ & 27 & 25.71 \\
\hline$] 40,50]$ & 34 & 32.38 \\
\hline$] 50,60]$ & 26 & 24.76 \\
\hline$] 60,70]$ & 11 & 10.40 \\
\hline$] 70,80]$ & 2 & 1.91 \\
\hline Marital Status & & 30.48 \\
\hline Single & 32 & 30.48 \\
\hline Married & 60 & 57.14 \\
\hline Divorced & 4 & 3.81 \\
\hline Widow & 9 & 8.57 \\
\hline \multicolumn{3}{|l|}{ Region } \\
\hline Grand North & 6 & 5.71 \\
\hline Grand South & 49 & 52.37 \\
\hline Littoral/South West & 4 & 3.81 \\
\hline West/North-West & 46 & 43.81 \\
\hline \multicolumn{3}{|l|}{ Level of Education } \\
\hline Unschooled & 6 & 5.71 \\
\hline Primary & 19 & 18.10 \\
\hline Secondary & 48 & 45.71 \\
\hline University & 32 & 30.48 \\
\hline \multicolumn{3}{|l|}{ Sex } \\
\hline Woman & 104 & 99.05 \\
\hline Man & 1 & 0.95 \\
\hline \multicolumn{3}{|l|}{ Residence } \\
\hline Rural & 22 & 20.95 \\
\hline Urban & 83 & 79.05 \\
\hline \multicolumn{3}{|l|}{ Profession } \\
\hline Student & 7 & 6.67 \\
\hline Housewife & 34 & 32.38 \\
\hline Informal Sector & 27 & 25.71 \\
\hline Salaried & 32 & 30.48 \\
\hline Retired & 5 & 4.76 \\
\hline
\end{tabular}


Table 2. Distribution of study participants with respect to socio-economic characteristics.

\begin{tabular}{ccc}
\hline Socio-economic characteristic & $\begin{array}{c}\text { Number } \\
(\mathrm{N}=105)\end{array}$ & Percentage \\
\hline $\begin{array}{c}\text { Monthly income } \\
<175 \text { USD }\end{array}$ & 75 & 71.43 \\
$\geq 175$ USD & 30 & 28.57 \\
Financial help & & \\
No & 11 & 10.48 \\
Yes & 94 & 89.52 \\
Monthly expenditure on breast cancer & & 37.14 \\
$<175$ USD & 39 & 62.86 \\
$>175$ USD & 66 & \\
Health insurance & & 97.14 \\
No & 102 & 2.86 \\
Yes & 3 &
\end{tabular}

Table 3. Distribution of patients with respect to stage of disease and histological type.

\begin{tabular}{ccc}
\hline Variables & $\begin{array}{c}\text { Number } \\
(\mathrm{N}=105)\end{array}$ & Percentage \\
Stage & 9 & \\
Stage 1 & 22 & 8.57 \\
Stage 2 & 29 & 20.95 \\
Stage 3 & 45 & 27.62 \\
Stage 4 & & 42.86 \\
Histological types & 101 & \\
Invasive ductal carcinoma & 4 & 3.1 \\
Others & & 96.90 \\
\hline
\end{tabular}

Table 4. Distribution of patients with respect to their knowledge of breast cancer.

\begin{tabular}{ccc}
\hline Knowledge of the patients & $\begin{array}{c}\text { Number } \\
(\mathrm{N}=105)\end{array}$ & Percentage \\
\hline Definition of breast cancer & 38 & 36.19 \\
No & 67 & 63.81 \\
Yes & & \\
Risk factors of breast cancer & 57 & 33.33 \\
Natural & 6 & 5.71 \\
\hline
\end{tabular}




\section{Continued}

Mixed

Symptoms of breast cancer

No symptom

39

37.14

Axillary mass

Abnormality of the nipple

Breast pain

Nipple discharge

Breast tumefaction

Breast nodule

Sex with high risk of breast cancer

Female

Both sexes

76

29

27.62

Age with high risk for breast cancer

Don't know

All ages

Know of a screening method

No
Yes

Curability of breast cancer

Unknown
No
Yes

Know of treatment available

$\begin{array}{lll}\text { No } & 21 & 20.00 \\ \text { Yes } & 84 & 80.00\end{array}$

Table 5. Determinants of the first diagnostic choice at discovery of initial symptoms of breast cancer.

\begin{tabular}{cccccc}
\hline $\begin{array}{c}\text { Characteristics } \\
\text { of patients }\end{array}$ & $\begin{array}{c}\text { Contemporary } \\
\text { Medicine }\end{array}$ & $\begin{array}{c}\text { Other } \\
\text { choices }\end{array}$ & Total & $\begin{array}{c}\text { RC } \\
(\mathrm{IC}=95 \%)\end{array}$ & $\mathrm{p}$ \\
\hline Monthly income & & & & & \\
& 32 & 43 & 75 & 1 & - \\
<175 USD & $(61.5)$ & $(81.1)$ & & & \\
& 20 & 10 & 30 & 0.37 & 0.028 \\
& $(38.5)$ & $(18.9)$ & & $(0.15-0.89)$ & \\
\hline
\end{tabular}




\section{Continued}

Standard of living

$\begin{array}{cccccc}\text { Low } & 24 & 37 & 61 & 1 & - \\ & (46.2) & (69.8) & & & \\ \text { Average } & 28 & 16 & & 0.37 & 0.015\end{array}$

Level of knowledge

on breast cancer

$\begin{array}{cccccc}\text { Poor } & 6 & 11 & 17 & 1 & - \\ & (11.5) & (20.8) & & & \\ \text { Insufficient } & 8 & 18 & & 1,23 & 0.757 \\ & (15.4) & (34) & 26 & (0.33-4.51) & \\ \text { Average } & 9 & 9 & & 0.55 & 0.381 \\ & (17.3) & (17) & 18 & (0.13-2.09) & \\ \text { Good } & 29 & 15 & & 0.28 & 0.034\end{array}$

Time since diagnosis

of breast cancer

(months)

$\begin{array}{cccccc}\leq 6 & 17 & 8 & 25 & 1 & \\ & (32.7) & (15.1) & & & \\ 16-12] & 11 & 12 & & 2.32 & 0.160 \\ & (21.2) & (22.6) & 23 & (0.73-7.75) & \\ 112-36] & 19 & 18 & & 2.01 & 0.195 \\ & (36.5) & (34) & & (0.71-6.01) & \\ >36 & 5 & 15 & & 6.37 & 0.005 \\ & (9.6) & (28.3) & 20 & (1.81-25.8) & \end{array}$

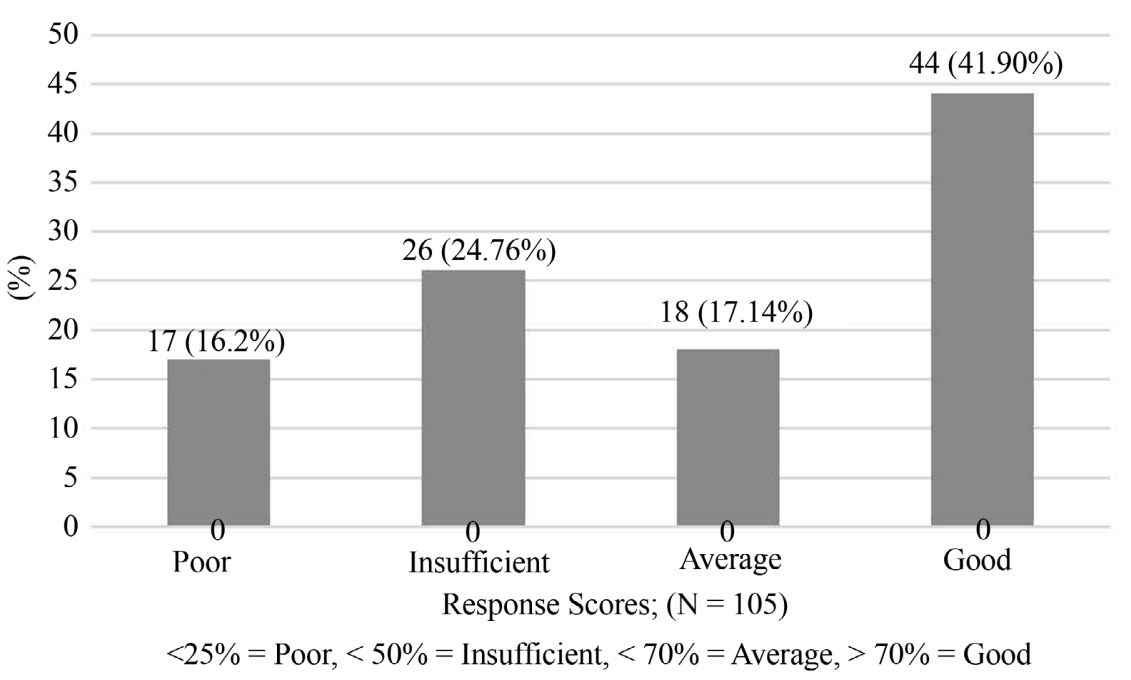

Figure 1. Distribution of participants with respect to their knowledge scores on breast cancer. 
Table 6. Distribution of patients according of reasons for making choices.

\begin{tabular}{ccc}
\hline Reasons for choosing a option & $\begin{array}{c}\text { Number } \\
(\mathbf{N}=105)\end{array}$ & Percentage \\
\hline Advice from a relative & 38 & $35.19 \%$ \\
Advice from a health care professional & 9 & $8.57 \%$ \\
Personal initiative & 50 & $47.62 \%$ \\
\hline
\end{tabular}

those who chose at first recourse a modality other than conventional medicine, at second recourse, they chose conventional medicine in $85 \%, 80 \%$, and $100 \%$ respectively for those of abstention group, of self-medication and of naturopathy/traditional medicine groups (Figure 2).

After confirmed diagnosis of breast cancer, the patients had different itineraries in their search for a therapeutic solution. The patients' first therapeutic recourse was contemporary medicine in $65.7 \%$, naturopathy in $15.2 \%$, traditional medicine in $9.5 \%$, religious practices in $4.8 \%$, therapeutic abstention in $2.9 \%$ and self-medication in $1.9 \%$. At second therapeutic recourses', majority of patients who chose initially an modality other than contemporary Medicine at first therapeutic recourse at second recourse chose contemporary medicine in $99 \%, 80 \%$, $40 \%, 66.7 \%$ and $100 \%$ respectively for those of naturopathy group, traditional medicine, religious practices, therapeutic abstention and self-medication (Figure 3).

\section{Discussion}

The objective of the present study was to determine among women followed up for breast cancer in two referral hospitals in Yaounde, their diagnostic and therapeutic choices. We found that the first and second diagnostic and therapeutic choices of these patients in our environment are varied and include contemporary medicine, naturopathy, therapeutic abstention, self-medication, traditional medicine, religious practices in various proportions.

The median age of patients was 46 years with extremes ranging between 25 and 77 years which is consistent with the results of other African studies in Cameroon by Kemfang et al. ( $47.5 \pm 12.36$ years), Engbang et al. ( $46.80 \pm 15.87$ years) and in Mali by Ly et al. ( $46.0 \pm 19.6$ years) in which it is reported that the young age of breast cancer patients is due certainly to the low life expectancy of Africans compared to Caucasians and probably genetic factors predisposing to early breast cancer [7] [12] [13].

In our study, almost half of patients had studied up to high school level (45.71\%) which is different from those reported by Benbakhta et al. in Morocco, where $56 \%$ were illiterates [14]. The difference is probably due to the cultural and religious differences that exist in these two countries. The level of education has a fundamental impact on the different behaviours exhibited by humans in the society, the more the population is educated, the more the utilization of 

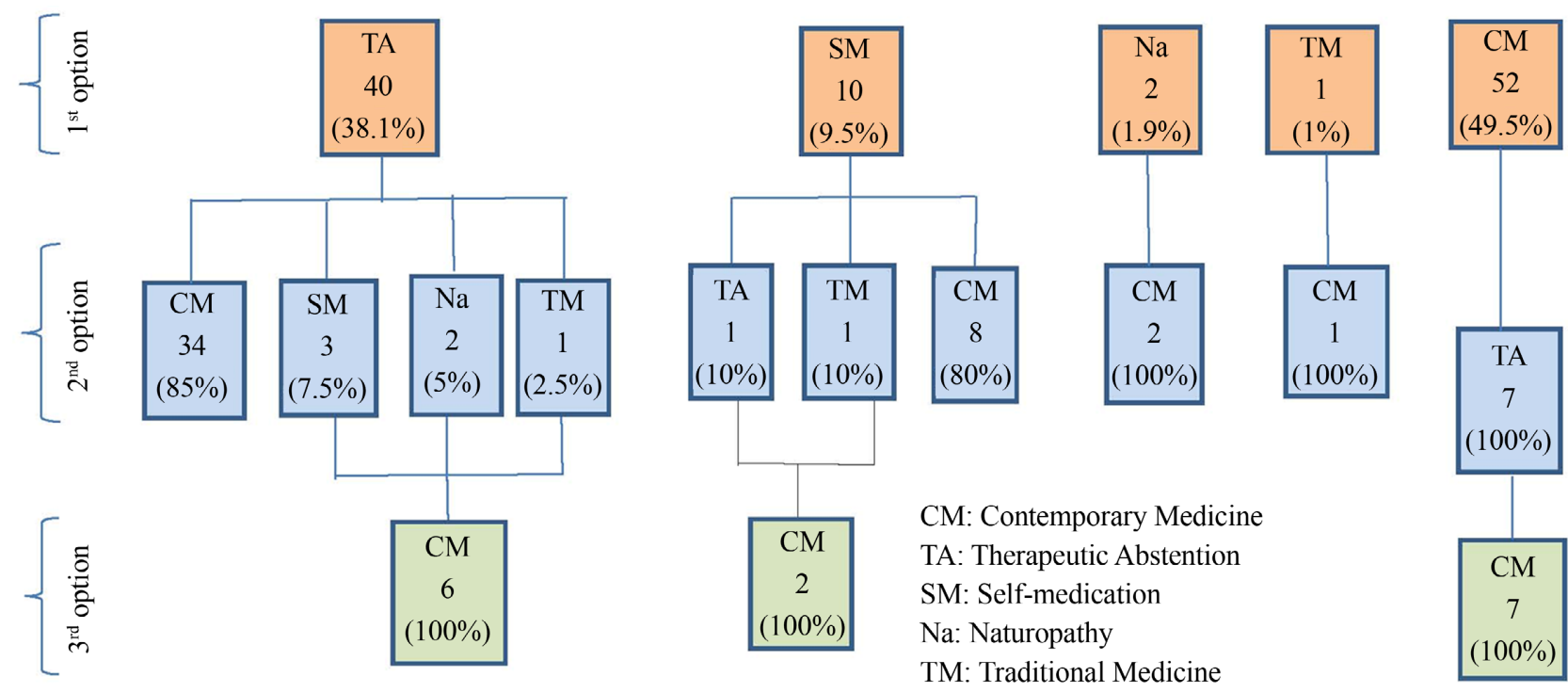

Figure 2. Diagnostic itineraries of the patients after initial symptoms.
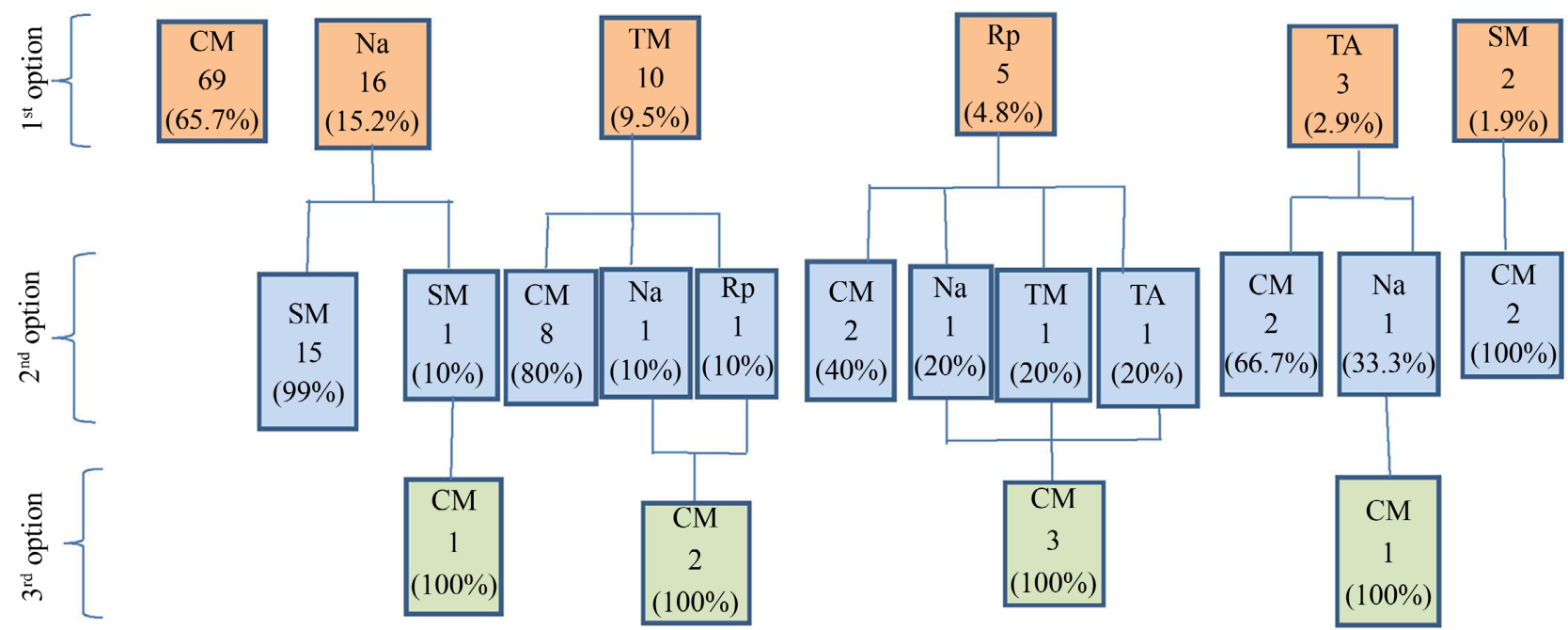

CM: Contemporary Medicine

TA: Therapeutic Abstention

SM: self-medication

Na: Naturopathy

TM: Traditional Medicine

Rp: Religious practices

Figure 3. Therapeutic itineraries of patients at confirmed diagnosis of breast cancer.

modern health care facilities and the lesser the usage of traditional medicines [15].

Most of the patients $71.43 \%$ had a low level of monthly income and $58.10 \%$ had a low standard of living. Consequently, $73.33 \%$ of the patients reported that the cost of treatment was very high. These results are similar to those reported in Benin and Senegal and confirm the low socio-economic level of our African population in general and sub-Saharan African populations in particular [16].

In this study, contemporary medicine, therapeutic abstention, self-medication, 
traditional medicine and naturopathy were among the choices made as diagnostic option. Zannou et al. in Benin have had similar results with various diagnostic options including traditional medicine, religious practices and contemporary medicine [16]. The first choice is the stage in which significant differences are observed in the itineraries of the patients [9]. As the first diagnostic choice, about half of the patients $50.58 \%$ in the present study did not chose contemporary medicine. This is similar to what was reported in Benin by Zannou et al., where more than half of the participants had initially consulted traditional medicine [16].

Concerning therapeutic options, the choices identified were contemporary medicine, self-medication, abstention, naturopathy, traditional medicine and religious practices. The therapeutic itineraries of the patients were very long with some using about three options for their care.

Cultural, educational, financial and geographic factors may influence the diagnostic and therapeutic choices of patients. In this study, monthly income greater than 175 USD; OR. 0.37 (0.15 - 0.89), average of standard of living; OR. 0.37 $(0.16-0.82)$ and good knowledge on the disease; OR. 0.28 (0.08 - 0.89) were significantly associated to choosing contemporary medicine as first recourse. Limited access to the funding and the high cost of medical care are among the reasons for the long delay in initiating therapy after diagnosis in our study population. This also includes expenses on transport and other costs like feeding and the living costs of accompanying persons [13] [15]. Fear of breast cancer treatment was also recorded as one of the reasons for choosing non-contemporary medicine. The patients feared losing an essential organ of their body that is tightly linked to their femininity through mastectomy. They feared becoming Half Women and subdue the social pressures associated with it. This was more common in the married women who constituted the majority of our study population with $57.14 \%$. The participants also feared chemotherapy, viewing it as too aggressive and thought it could cause death. Belief in spiritual healing by the patients caused them to use traditional medicine and religious practices as a therapeutic recourse; and this is more so because they attributed a mystical origin to their disease. A patient made the following declaration in this light "I did not have enough money to do the tests I was asked to do... I spoke about it to my Pastor and we started prayer sessions, he gave me oil to rub on the breast. The lump kept growing..., when I had money, I came back to the hospital'.

Self-medication was observed in $9.52 \%$ of patients in this study. They did not regard their symptoms as serious and thought they were benign or of infectious origin. These same considerations were reported by authors in Mali and in Be$\operatorname{nin}[13]$ [16].

Being a hospital-based study was the major limit of our study as we could recruit only patients who at some point in their itinerary decided to come to the hospital and excluded all those who never began care in a hospital setting. 


\section{Conclusions}

The first diagnostic and therapeutic choices of breast cancer patients in our setting are numerous and intricate including contemporary medicine, therapeutic abstention, self-medication, traditional medicine, naturopathy and religious practices. Only a half of breast cancer patients choose as the first recourse to consult at a health center.

A good level of education, monthly income greater than 175 USD and good knowledge of breast cancer are the main factors significantly associated with choosing contemporary medicine as a first diagnostic option at the time of initial symptoms.

There is a need to inform and educate our population on the importance of screening, early diagnosis and adequate treatment of breast cancer and also the need for the establishment of universal health coverage in our environment to improve the access to breast cancer care.

\section{Conflicts of Interest}

The authors declare no conflicts of interest.

\section{References}

[1] Bray, F., Ferlay, J., Soerjomataram, I., Siegel, R., Torre, L. and Jemal, A. (2018) Global Cancer Statistics 2018: GLOBOCAN Estimates of Incidence and Mortality Worldwide for 36 Cancers in 185 Countries. CA: A Cancer Journal for Clinicians, 68, 2893-2917.

[2] Akuoko, C.P., Armah, E., Sarpong, T., Quansah, D.Y., Amankwaa, I. and Boateng, D. (2017) Barriers to Early Presentation and Diagnosis of Breast Cancer among African Women Living in Sub-Saharan Africa. PLoS ONE, 12, Article ID: e0171024.

[3] Ly, M., Ly, A., Rodrigues, M., Loriot, Y., Deberne, M., Boudou-Rouquette, P., et al. (2010) Cancer in Africa, a New Health Challenge. Examples of Mali and OncoMali. Bull Cancer, 97, 965-968.

[4] Unger-Saldaña, K. (2014) Challenges to the Early Diagnosis and Treatment of Breast Cancer in Developing Countries. World Journal of Clinical Oncology, 5, 465-477.

[5] Sando, Z., Fouogue, J.T., Fouelifack, F.Y., Fouedjio, J.H., Mboudou, E.T. and Essame, J.L. (2014) Profil des cancers gynécologiques et mammaires à Yaounde-Cameroun. Pan African Medical Journal, 17, Article No. 28.

[6] Ngowa, J.D.K., Yomi, J., Kasia, J.M., Mawamba, Y., Ekortarh, A.C. and Vlastos, G. (2011) Breast Cancer Profile in a Group of Patients Followed up at the Radiation Therapy Unit of the Yaounde General Hospital, Cameroon. Obstetrics and Gynecology International, 2011, Article ID: 143506.

[7] Kemfang, J.D., Kasia, J.M., Yomi, J., Nkigoum, A., Ngassam, A., Domkam, I., et al. (2015) Breast Cancer Survival in Cameroon: Analysis of a Cohort of 404 Patients at the Yaounde General Hospital. Advances in Breast Cancer Research, 4, 720-726.

[8] Hortobagyi, G.N., de la Garza Salazar, J., Pritchard, K., Amadori, D., Haidinger, R., Hudis, C.A., et al. (2005) The Global Breast Cancer Burden: Variations in Epidemiology and Survival. Clinical Breast Cancer, 6, 391-401.

[9] Nkoma, P.P. (2015) Itinéraires thérapeutiques des malades au Cameroun. 7ème Conférence sur la Population Africaine. In: Dividende Démographique en Afrique. Perspectives, Opportunités et Défis, Le Gouvernement de l'Afrique du Sud et l'Union pour 
l'Etude de la Population Africaine (UEPA), Johannesburg.

[10] International Agency for Research on Cancer (2020) 20-Cameroon-Fact-Sheets. http://gco.iarc.fr/today/data/factsheets/populations/120-cameroon-fact-sheets.pdf

[11] Essi, M. and Njoya, O. (2013) L’Enquête CAP (Connaissances, Attitudes, Pratiques) en Recherche Médicale. Health Sciences and Disease, 14, 136-138.

[12] Engbang, J.P., Essome, H., Koh, V.M., Simo, G., Essam, J.D., Mouelle, A.S., et al. (2015) Cancer du sein au Cameroun, profil histo-épidémiologique: A propos de 3044 cas. Pan African Medical Journal, 21, Article No. 242.

[13] Ly, M., Diop, S., Sacko, M., Baby, M., Diop, C.T. and Diallo, D.A. (2002) Breast Cancer: Factors Influencing the Therapeutic Itinerary of Patients in a Medical Oncology Unit in Bamako (Mali). Bulletin du Cancer, 89, 323-326.

[14] Benbakhta, B., Tazi, M., Benjaafar, N., Khattabi, A. and Maaroufi, A. (2015) Déterminants des délais patient et système de santé des femmes atteintes d'un cancer du sein au Maroc, 2013. Revue dépidémiologie et de Santé Publique, 63, 191-201.

[15] Ngowa, J.D.K., Kabeyene, A., Ngarvounsia, R., Atenguena, E., Tchawe, Y.S.N., Ngassam, A., Nsahlai, C., Metogo, J., Tsuala, J.F. and Tebeu, P.M. (2020) Consultation, Diagnosis and Treatment Delays for Breast Cancer among Patients Followed up at the Yaounde General Hospital, Cameroon. Open Journal of Obstetrics and Gynecology, 10, 1580 1589.

[16] Zannou, D.M., Prudencio, R.D.T.K, Azon-Kouanou, A., Agbodandé, K.A., Vigan, J., Houngbé, C., Adé, G. and Houngbé, F. (2015) Itinéraire thérapeutique et retard à la consultation des patientes atteintes du cancer du sein au centre national hospitalier et universitaire Hubert K Maga cotonou (Bénin). RAFMI, 2, 24-28. 